\title{
The Inhomogeneous Distribution of the Corticostriatal Fibers Originating from the Frontal and Parietal Cortices: An Autoradiographic Study in the Rat*
}

\author{
By \\ Kazuo WATANABE \\ Department of Anatomy, Hamamatsu University School of Medicine, \\ 3600 Handa-cho, Hamamatsu 431-31, Japan \\ - Received for Publication, March 19, 1984 -
}

\begin{abstract}
Key Words: Striatum, Frontal cortex, Parietal cortex, Corticostriatal connection, Rat, Autoradiography

Summary: Corticostriatal fibers were traced from the frontal and parietal cortices and from other cortical areas in the rat, using the autoradiographic method. Although the patterns of fiber termination from the frontal and parietal cortices varied in some degree from each other, inhomogeneous distribution was a common feature of both fiber systems. Fibers from the frontal cortex spread themselves throughout the anteroposterior extent of the striatum. In the anterior portion of the striatum, labeling was distributed densely, but there were sparsely labeled patches in the densely labeled region. In the posterior portion, corticostriatal fibers terminated forming bands or patches. Parietostriatal fibers were distributed mainly in the posterior half of the striatum. These terminated densely in narrow bands, which were situated in the dorsolateral portion of this nuclear complex. These results provide good evidence for the heterogeneous organization of the striatum, which is well established in higher animals. After injections of isotopes into the parietal cortex with involvement of the hippocampal formation or cingulate cortex, silver grains were distributed sparsely in the striatum and no evidence for such an uneven distribution was not observed.
\end{abstract}

Although the striatum was regarded as a homogeneous structure, its heterogeneous organization has been recently demonstrated in humans (Graybiel and Ragsdale, 1978), primates (Künzel, 1975, 1977; Goldman and Nauta, 1977; Graybiel and Ragsdale, 1978; Yetterian and Van Hoesen, 1978; Jones et al., 1981; Ragsdale and Graybiel, 1981; Van Hoesen et al., 1981; GoldmanRakic, 1982; Haber and Elde, 1982;Wamsley et al., 1982) and carnivora (Graybiel and Ragsdale, 1978; Graybiel et al., 1979, 1981; Royce, 1979; Ragsdale and Graybiel,
1981; Battaglini et al., 1982; Reale and Imig, 1983; Tanaka, 1983). Graybiel and Ragsdale (1978) found that the striatum is composed of two sorts of compartment showing low (striosome) and high acetylcholinesterase (AChE) activity in the human. monkey and cat. After that time, her group showed the intimate relationships between these compartmental structures and the distributions of afferent fibers from the cerebral cortex (Ragsdale and Graybiel, 1981), of cells giving rise to the striatal efferent fibers (Graybiel et al., 1979), and

*Dedicated to Prof. Dr. Hiroshi Kinefuchi in honor of his retirement from the Faculty of Education. Niigata University. 
of some neuropeptides (Graybiel et al., 1981). They showed, at least in the cat, that this inhomogeneity is an essential feature of the striatal organizaion in anatomical, physiological and pharmacological aspects.

In the rat, the patch-like or inhomogeneous distributions of thalamostriatal (Herkenham and Pert, 1981; Gerfen et al., 1981) and amygdalostriatal fibers (Kelley et al., 1982), opiate receptors (Atweh and Kuhar, 1977; Herkenham and Pert, 1981; Van Hoesen et al., 1981; Unnerstall et al., 1983), enkephalin (Sar et al., 1978; Williams and Dockray, 1983) and dopamine (Olsson et al., 1972) have been demonstrated. Some authors (Butcher and Hodge, 1976; Graybiel and Ragsdale, 1979) reported that AChE was distributed homogeneously in the striatum of the adult rat, while Herkenham and Pert (1981) have recently shown the heterogeneous distribution of AChE activity. Although the corticostriatal connection has been investigated by nunerous workers in higher animals (Künzel, 1975, 1977; Goldman and Nauta, 1977; Jones et al., 1977; Yetterian and Van Hoesen, 1979; Ragsdale and Graybiel, 1981; Van Hoesen et al., 1981; Battaglini et al., 1982; Goldman-Rakic, 1982; Tanaka, 1983), only a little information has been available for rodents, and some previous investigators have reported that corticostriatal fibers from the frontal or parietal cortex are distributed diffusely (Goldman-Rakic, 1982; Porter and White, 1982). This propounds a question wether or not a striosomal structure is really present in the striatum of the rat. The main purpose of the present investigation was to reexamine the distribution of corticostriatal fibers utilizing the autoradiographic method (Cowan et al., 1972), because early evidence for the inhomogeneity of the striatum was obtained from the autoradiographic investi- gations on the distribution of corticostriatal fibers originating from the frontal and parietal cortices in higher animals (Künzel, 1975, 1977; Goldman, 1977; Jones et al., 1977; Yetterian and Van Hoesen, 1978).

\section{Materials and Methods}

In this experiment, Wistar strain male rats ( 8 weeks old) were used. An equal part mixture of $\mathrm{L}-\left[5,3 \cdot{ }^{3} \mathrm{H}\right]$ leucine and $\mathrm{L}-\left[5{ }^{3} \mathrm{H}\right]$ proline (Amersham) was dried in an air stream, and redissolved in distilled water or $0.9 \%$ saline at a final concentration ranging from $50-100 \mu \mathrm{Ci} / \mu \mathrm{l}$. Under anaesthesia with pentobarbital $(35 \mathrm{mg} / \mathrm{kg})$, isotopes were injected into the cerebral cortex of 17 rats by means of an $1-\mu 1$ Hamilton syringe at a rate of $0.02 \mu \mathrm{l} / \mathrm{min}$. Isotopes were deposited in the frontal cortex ( 9 rats), occipital cortex (3 rats), frontal and parietal cortices (1 rat), frontal and cingulate cortices (2 rats), occipital cortex and subiculum (1 rat), or occipital and cingulate cortices (1 rat). After 5 or 7 days, the rats were fixed by perfusion with $20 \%$ formalin under deep anaesthesia. Their brains were dissected out from the skulls, postfixed in $20 \%$ formalin for 3-7 days, and embedded in gelatin (Blackstadt et al., 1981). They were then cut serially on a freezing microtome at $40 \mu \mathrm{m}$ in the frontal plane of Pellegrino et al. (1979). Two sets of sections at $200-\mu \mathrm{m}$ intervals were mounted on gelatin-coated glass slides, defatted in xylene, and hydrated through descending concentrations of alcohol and through water. They were then coated with an autoradiographic emulsion (MR-M2, Konisiroku, Tokyo) and stored in light-proof boxes at $4^{\circ} \mathrm{C}$. After $4-16$ weeks, the autoradiograms were developed with Konidole $\mathrm{X}$ for 4-6 minutes at $20^{\circ} \mathrm{C}$, fixed with Konifix (Konisiroku, Tokyo), and counterstained with a $0.2 \%$ cresyl violet solution. 
The injection site as well as distribution of terminal labeling were examined under both bright- and dark-field illuminations.

Many authors make a distinction between the nucleus accumbens and the caudatoputamen. But it is not always easy to define the limites of the nucleus accumbens using cytoarchitectural as well as hodological criteria; i.e., fibers from the amygdala (Kelley et al., 1982) and neocortex terminate in both the caudatoputamen and the nucleus accumbens. So in this investigation, the nucleus accumbens is not especially distinguished from the remainder of the striatum.

\section{Results}

The following descriptions are based on the experiments in which an animal received an injection of a large amount of tritiated amino acids $(15-20 \mu \mathrm{Ci})$ and the autoradiograms were exposed for a long time (10-16 weeks). Under these conditions, the autoradiograms revealed an inhomogeneous distribution of fibers originating from the frontal and parietal cortices, while, under conditions of an injection of a small amount of isotopes $(5 \mu \mathrm{Ci})$ and a short exposure time (4-6 weeks), the corticostriatal fibers were appeared to be distributed sparsely and diffusely. That is, a high density of silver grains was needed to show the inhomogeneous distribution of corticostriatal fibers.

An inhomogeneous distribution of corticostriatal fibers was noticed typically in analyses of fronto- and parietostriatal connections. So in the following description, these two pathways will be described in detail. Additionally, corticostriatal fibers from the posterior portions of the cortical hemisphere will be described.

\section{Projection from the frontal cortex}

Fibers originating from the frontal cortex were distributed more extensively in the striatum on both sides than had been regarded previously in degeneration studies (Webster, 1961), and were not homogeneously distributed. Although some topographical differences were noticed among the experiments, frontostriatal fibers from various loci exhibited essentially similar distributional features. In the following paragraphs, a representative experiment, RA83, will be described in detail.

In RA83, isotopes were deposited densely in layers I-V and an upper portion of layer VI in area 10 of Krieg (1946) or the medial agranular prefrontal cortex of Donogue and Wise (1982) (Fig. 1). Ipsilaterally, labeled fibers traversed the cortical white matter and entered the caudatoputamen. Some of the labeled fibers passed the striatum through numerous compact fasciculi of the internal capsule.

Corticostriatal fibers were spread throughout the antero-posterior extent of the striatum. In the anterior two-fifths of the striatum, silver grains were densely packed in the lateral two thirds (Fig. 2). Sparsely labeled patches were scattered in the densely labeled region except the most anterior

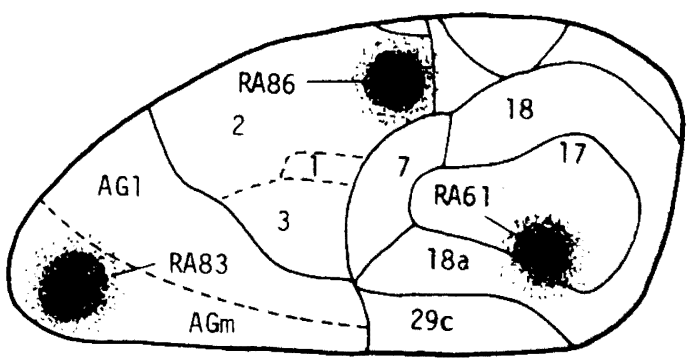

Fig. 1. Dorsal view of cerebral hemisphere showing injection sites of tritiated amino acids (dotted areas) in the frontal (RA83), parietal (RA64) and occipital (RA61) cortices. Nomenclatures used for the frontal field are after Donghue and Wise (1982), and those for the other fields are after Krieg (1946). AGl, lateral agranular frontal cortex; AGm, medial agranular frontal cortex. 
portion. Their shapes and sizes varied considerably (150-300 $\mu \mathrm{m}$ wide). They showed irregular appearances, and had no sharp border or surroundings. These sparsely labeled patches were similar in shape to "striosomes" described in the cat (Graybiel and Ragsdale, 1978). These were not unlabeled fiber bundles of the internal capsule but contained numerous cells. The number of cells ranged from about 30 in a small patch to more than 100 in a large one. No special relationships were observed between the locations of the striosome-like structures and the fasciculi of the internal capsule. Occasionally, a cell group in a sparsely labeled patch was separated from its surroundings by a cell-sparse zone (capsule of Goldman-Rakic, 1982), but, in general, such capsules were not observed. This cell-sparse zone also contained numerous silver grains. Although the striosome-like structures could be distinguished from their surroundings by their density and cell orientation, their locations were difficult to predict cytoarchitectually without the aid of autoradiograms.

At the midlevels, these striosome-like structures became indistinct. Dense and homogeneous labeling was located in the dorsolateral portion of the striatum. Silver grains formed a lamella at the peripheral zone of the striatum in contact with the cerebral white matter (Fig. 3). This thin labeled zone extended to the ventrolateral border of the striatum. The silver grains also aggregated in patchy or lamella-like clusters in the ventromedial portion of the striatum (Fig. 3B). Although silver grains were distributed irregularly in the posterior portions of the striatum, they became concentrated in two or three large bands arranged parallel to the dorsolateral surface of the globus pallidus or to the white matter of the cortex (Fig. 4A). Sparsely labeled bands lay between densely labeled ones. At the level of the posterior one-fourth of the striatum, silver grains decreased in density, and were distributed more homogeneously (Fig. 4B). Sparse labeling was also observed in the ventral portion of the striatum, the labeling of which was continuous with that of the amygdala.

It may be worth noting the relationship between the distributions of passing internal capsular fibers and those of corticostriatal fibers, both of which arose from the same cortical locus. The region in which the two fiber systems were distributed was restricted within narrow limits. In the other extensive region of the striatum, each of the fiber systems occupied its own location (see Figs. 2B, 3A and B).

Labeled fibers crossed the midline through the corpus callosum at its anterior portion, and entered the contralateral striatum. The labeling pattern in the contralateral striatum was essentially similar to that in the ipsilateral one, but the density of silver grains was lower than in the latter. Few silver grains were observed in the fasciculi of the internal capsule.

\section{Projection from the parietal cortex}

Fibers from the parietal cortex were distributed in the ipsilateral striatum, and no substantial labeling was detected in the contralateral one. The density of labeling transported from the parietal cortex was lower than that from the frontal cortex. In the ipsilateral striatum, labeled fibers were spread extensively in the striatum, but they tended to concentrate posteriorly as compared with frontostriatal fibers. In the posterior one-third of the striatum, silver grains were distributed densely in the dorsolateral part of the striatum, tending to form a lamellar pattern. In the following paragraphs, a representative experiment, RA86, will be described in detail.

In RA86, isotopes were deposited in all layers of the posterior portion of area 2 of Krieg (1946) or the posterior portion 
of the primary somatosensory area (Fig. 1). Numerous labeled fibers traversed anteriorly and entered the internal capsule at the caudal portion of the striatum. Labeled fibers were found all over the anteroposterior extent of the ipsilateral striatum. In the posterior portion of the caudatoputamen, transported label was found densely in the dorsolateral portion (Fig. 5A) and sparsely in the ventrolateral portion. Labeling formed a dense and narrow band approximately $300 \mu \mathrm{m}$ wide. It was pierced by unlabeled passing fiber bundles, so that it was divided into several small fragments. It may be worth noting that these labeled regions were not in direct contact with the cerebral white matter, but sparsely labeled zone was interposed between them. Rostrally, this densely labeled zone became wider, before spliting into two or three irregular lamellae (Fig. 5B).

In the middle one-third, silver grains decreased in density and were distributed in the dorsal and lateral parts. Although labeled fibers were distributed more homogeneously at this level than at the more posterior, the striosome-like structures could be observed to some extent. At more anterior levels, the density of labeling decreased considerably, and inhomogeneity of distribution could not be observed. At the rostral tip of the striatum, sparse labeling was located in the lateral portion.

\section{Projections from the occipital and adjacent cortices}

The density of labeling in the striatum transported from the occipital cortex was lower than that from the frontal and parietal cortices. In an experiment, RA61, isotopes were deposited densely in layers $\mathrm{V}$ and VI of areas 17 and 18 of Krieg (1946) and hippocampus (Fig. 1). Labeled fibers traversed anteriorly through the cortical white matter, and entered the most caudal portion of the internal capsule. Silver grains were sparsely distributed in the dorsal portion of the posterior one-half of the striatum. They did not show any signs of inhomogeneous distribution. Discrete labeling was also found in the most anterior portion of the striatum. This region did not show any apparent patchlike or striosomal structures. Sparse labeling was also observed in the contralateral striatum. Labeling was also found in the fornical fiber system, but these fibers did not enter the caudatoputamen.

In an experiment, RA58, isotopes were deposted in areas 18, 29b and 29c of Krieg (1946). The results were essentially similar to those of RA61, except that labeling was not detected in the fornical fiber system.

\section{Discussion}

Using the autoradiographic tract tracing method, recent investigators have revealed an important feature of the corticostriatal projections in the primate (Künzel, 1975, 1977; Goldman and Nauta, 1977; Jones et al., 1977; Kalil, 1978; Yetterian and Van Hoesen, 1978; Goldman-Rakic, 1981; Ragsdale and Graybiel, 1981; Van Hoesen, 1981) and carnivora (Ragsdale and Graybiel, 1981; Battaglini et al., 1982; Reale and Imig, 1983; Tanaka, 1983); corticostriatal fibers are not distributed homogeneously, but show a clustered or discontinuous appearance. However, this aspect of striatal organization has not been investigated in the rodent, where the uneven distribution of striatal afferents originating from the frontal cortex was reported concomitantly in the region of the nucleus accumbens (Beckstead, 1979). In the region of the caudatoputamen, fibers from the frontal and parietal cortices were regarded to be distributed diffusely or homogeneously (Goldman-Rakic, 1982; Porter and White. 
1983), or such a heterogeneous organization was not described (Beckstead, 1979; Dalsass et al., 1981; White and DeAmices, 1977). The present results in the rat showed that afferent fibers from the frontal and parietal cortices terminated in a widespread region of the striatum including the nucleus accumbens. Differences between the results of the present investigation and those of previous ones (White and DeAmicis, 1977; Beckstead, 1979; Dalsass et al., 1981; Goldman-Rakic, 1982; Porter and White, 1983) could be attributed to differences between the respective experimental procedures, because dense labeling is needed to show clearly the heterogeneous distribution of the corticostriatal fibers in the rat. An inhomogeneous distribution of the corticostriatal fibers was also reported concomitantly in investigations on the efferent projection of the insular cortex of the rat (Saper, 1982) and hamster (Reep and Winans, 1982). As a consequence, it could be concluded that inhomogeneous distribution of corticostriatal fibers is an essential feature in the rodent as in the primate (Künzel, 1975, 1977; Goldman and Nauta, 1977; Jones et al., 1977; Kalil, 1978; Yetterian and Van Hoesen, 1978; Goldman-Rakic, 1981; Ragsdale and Graybiel, 1981; Van Hoesen and Yetterian, 1981) and carnivora (Ragsdale and Graybiel, 1981; Battaglini et al., 1982; Reale and Imig, 1983; Tanaka, 1983). This inhomogeneous distribution of the corticostriatal fibers may be comparable with the heterogeneous distributions of AChE (Herkenham and Pert, 1981), enkephalin (Sar et al., 1978; Williams and Dockray, 1983), opiate receptors (Pert et al., 1976; Atweh and Kuhar, 1977; Herkenham and Pert, 1981; Unnerstall et al., 1983), dopamine (Olson et al., 1972) and fibers from the thalamus (Herkanham, 1981; Gerfen et al., 1982) and amygdala (Kelley et al., 1982).
The distributional pattern of corticostriatal fibers varied considerably among the levels of the striatum. The striosomelike structures were distributed in a densely labeled region in the anterior portions of the striatum. In the posterior portions of this nuclear complex, corticostriatal fibers showed patch- or lamella-like distribution patterns. These results, together with a cytoarchitectural study in the mouse (Mensah, 1977), suggest that the differences between the anterior and posterior portions of the striatum are a general feature in the rodent. In the cytoarchitectural study of the striatum investigating the distribution of large cells and of two sorts of medium sized cell, Mensah (1977) showed differences between its anterior and posterior portions.

A cluster-like aggregation of striatal cells was reported in adult (Chronister et al., 1976; Mensah, 1977, 1980) and neonatal (Butcher and Hodge, 1976) rodents, but this could not be compared directly to the inhomogeneous distribution of corticostriatal fibers. The striatum of rodents is pierced by many fasciculi of the internal capsule, so that such clustering of cells (Chronister et al., 1976; Mensah, 1977,1980 ) could occur by an arrangement of these fasciculi (Mensah, 1977). Mensah (1977) observed cellular aggregations in the striatum of the mosue. These clusters contained 10-15 cells, and their cells were bordered by the fasciculi of the internal capsule or lay forming ring-like structures around the fasciculi, but differences among the clusters were not described. In this investigation, some cytoarchitectural differences were noticed between the striosomelike structures and their surroundings. But it is also difficult to distinguish the striosome-like structures from the matrix (Goldman-Rakic, 1982) in Nissl-stained sections without the aid of autoradiograms.

In the neonatal rat, clusters of neurons 
were intimately associated with $\mathrm{AChE}$ activity, which became more homogeneous during postnatal development (Butcher and Hodge, 1976). In contrast, opiate receptors are distributed homogeneously in the striatum of the neonatal rat. A patchlike distribution of these receptors emerges over a postnatal development period of about 2 weeks (Unnerstall et al., 1983). Thus, it is difficult to relate the cellular clustering in the striatum of neonatal rats to the striosome-like structure or the inhomogeneous distribution of corticostriatal fibers revealed in the present investigation.

Fibers from the posterior portion of the cerebral hemispheres were distributed diffusely in the striatum and showed no evidence of inhomogeneous distribution. It may be possible to consider this diffuse distribution as an essential one. But there remains the possibility that an uneven distribution could not be detected because of the low density of silver grains, as discussed in the above paragraph.

It is interesting to compare the distribution of corticostriatal fibers with that of opiate receptors shown by Atweh and Kuhar (1977). In the anterior portion of the striatum, striosome-like structures seemed to be related intimately, in shape and size, to patches exhibiting dense opiate binding (Atweh and Kuhar, 1977). In the posterior portion of the striatum, laminal structures showing dense opiate binding were arranged parallel to the cortical white matter. Corticostriatal fibers also terminated densely in bands which were arranged parallel to the cortical white matter. The outermost zone, in contact with the cortical white matter, showed dense opiate binding, and parietostriatal fibers appeared not to be terminated densely in this zone. However, it should be mentioned that frontostriatal fibers were present in this zone. It is therefore difficult to relate the sparsely labeled zone with the distribution of opiate receptors in the posterior portion of the striatum.

The present investigation revealed corticostriatal fibers to be distributed more extensively than regarded previously in the degeneration study of Webster (1961). The latter author reported that fibers from the frontal cortex terminated in the anterior half of the striatum, but the present investigation showed the frontostriatal fibers to be distributed all over the anteroposterior extent of this structure. Similar results indicating a more widespread distribution than that shown by degeneration studies have also been reported in the carnivora and primate (Van Hoesen et al., 1981).

\section{Acknowledgements}

I am indebted to Prof. Dr. E. Kawana for his kind consideration and advice concerning this investigation.

\section{References}

1) Atweh, S.F. and Kuhar, M.J.: Autoradiographic localization of opiate receptors in rat brain. III. The telencephalon. Brain Res., 134: 393-405, 1977.

2) Battaglini, P.P., Squatrito, S., Galletti, C., Maioli, M.G. and Riva Sanseverino, E.: Bilateral projections from the visual cortex to the striatum in the cat. Exp. Brain Res., 47: 28-32, 1982.

3) Beckstead, R.M.: An autoradiographic examination of corticocortical and subcortical projections of the mediodorsal-projection (prefrontal) cortex in the rat. J. comp. Neur., 184: 43-62, 1979.

4) Blackstadt, T.W., Heimer, L. and Mungaini, E.: Experimental neuroanatormy: General approaches and laboratory procedures. In Heimer, L. and Robards, M.J. (Eds.), Neuroanatomical Tract-Tracing Methods, Plenumm Press, New York, 1981, pp. 1-53.

5) Butcher, L.L. and Hodge, G.K.: Postnatal development of acetylcholinesterase in the caudato-putamen nucleus and substantia 
nigra of rats. Brain Res., 106: 223-240, 1976.

6) Chronister, R.B., Farnell, K.E., Marco, L.A. and White, L.E., Jr.: The rodent neostriatum: a Golgi analysis. Brain Res., 108: 37-46, 1976.

7) Cowan, W.M., Gottlieb, D.I., Hendrickson, A.E., Price, J.L. and Woolsey, T.A.: The autoradiographic demonstration of axonal connections in the central nervous system. Brain Res. 37 : 21-51, 1972.

8) Dalsass, M., Kiser, S., Mèndershausen, M., and German, D.C.: Medial prefrontal cortical projections to the region of the dorsal periventricular catecholamine system. Neurosci. 4: $657-665,1981$.

9) Donoghue, J.P. and Kitai, S.T.: A collaternal pathway to the neostriatum from corticofugal neurons of the rat sensory-motor cortex: An intracellular HRP study. J. comp. Neur., 201: 1-13, 1981.

10) Donoghue, J.P. and Wise, S.P.: The motor cortex of the rat: cytoarchitecture and microstimulation mapping. J. comp. Neur., 212: 76-88, 1982.

11) Gerfen, C.R., Staines, W.A., Arbuthnott, G.W. and Fibiger, H.C.: Crossed connections of the substantia nigra in the rat. J. comp. Neur., 207: 283-303, 1982.

12) Goldman, P.S. and Nauta, W.J.H.: An intricately patterned prefronto-caudate projection in the rhesus monkey. J. comp. Neur., 171: 369-386, 1977.

13) Goldman-Rakic, P.S.: Cytoarchitectonic heterogenity of the primate neostriatum: subdivision into island and matrix cellular compartments. J. comp. Neur., 205: 398-413, 1982.

14) Graybiel, A.M. and Ragsdale, C.W., Jr.: Histochemically distinct compartments in the striatum of human, monkey and cat demonstrated by acetylcholinesterase staining. Proc. nat. Acad. Sci. (Wash.), 75: 57235726, 1978.

15) Graybiel, A.M. and Ragsdale, C.W., Jr.: Fiber connections of the basal ganglia, In Cuénod, M., Kreutzberg, G.W. and Bloom, F.E. (Eds.), Development and Chemical Specificity of Neurons. Elsevier, Amsterdam, 1979, pp. 239-283.

16) Graybiel, A.M., Ragsdale, C.W., Jr. and Moon Edley, S.: Compartments in the striatum of the cat observed by retrograde cell labeling. Exp. Brain Res., 34: 189-195, 1979.
17) Graybiel, A.M., Ragsdale, C.W., Jr., Yoneoka, E.S. and Elde, R.P.: An immunohistochemical study of enkephalins and other neuropeptides in the striatum of the cat with evidence that the opiate peptides are arranged to form mosaic patterns in register with the striosomal compartments visible by acetylcholinesterase staining. Neurosci., 6: 377-397, 1981.

18) Haber, S. and Elde, R.: The distribution of enkephalin immunoreactive fibers and terminals in the monkey central nervous system: An immunohistochemical study. Neurosci., 7: 1049-1095, 1982.

19) Herkenham, R.M. and Pert, C.B.: Mosaic distribution of opiatoreceptors, parafascicular projections and acetylcholinesterase in rat striatum. Proc. nat. Acad. Sci. (Wash.), 291: 415-418, 1981.

20) Jones, E.G., Coulter, J.D., Burton, H. and Porter, R.: Cells of origin and terminal distribution of corticostriatal fibers arising in the sensory-motor cortex of monkeys. J. comp. Neur., 173: 53-80, 1977.

21) Kalil, K.: Patch-like termination of thalamic fibers in the putamen of the rhesus monkey: an autoradiographic study. Brain Res., 140: 333-339, 1978.

22) Kelley, A.E., Domesick, V.B. and Nauta, W.J.H.: The amygdalostriatal projectin in the rat - an anatomical study by anterograde and retrograde tracing methods, Neurosci., 7: 615-630, 1982.

23) Krieg, W.J.S: Connections of the cerebral cortex. I. The albino rat. A. Topography of the cortical areas. J. comp. Neur., 84: 221-275, 1946.

24) Künzle, H.: Bilateral projections from precentral motor cortex to the putamen and other parts of the basal ganglia. An autoradiographic study in Macaca fascicularis. Brain Res., 88: 195-209, 1975.

25) Künzle, H.: Projections from the primary somatosensory cortex to the basal ganglia and thalamus in the monkey. Exp. Brain Res., 30 : 481-492, 1977.

26) Mensah, P.L.: The internal organization of the mouse caudate nucleus: evidence for cell clustering and regional variation. Brain Res., 137: 53-66, 1977.

27) Mensah, P.L.: Distribution of the largest neuron in mouse caudate-putamen nucleus: its position in large-cell-medium- cell clusters, Exp. Brain Res., 38: 267-271, 1980.

28) Olson, L., Seiger, A., and Fuxe, K.: Hetero- 
geneity of striatal and limbic dopamine innervation: high fluorescent islands in developing and adult rats. Brain Res., 44: 283-288, 1972.

29) Pellegrino, J.L., Pellegrino, A.S. and Cushman, A.J.: Stereotaxic Atlas of the Rat Brain, Plenum Press, New York, 1979.

30) Pert, C.B., Kuhar, M.J. and Snyder, S.H.: Opiate receptor: autoradiographic localization in rat brain. Proc. nat. Acad. Sci. (Wash.), 73: 3729-3733, 1976.

31) Porter, L.L. and White, E.L.: Afferent and efferent pathways of the vibrissal region of primary motor cortex in the mouse. J. comp. Neur., 214: 279-289, 1983.

32) Ragsdale, C.W., Jr. and Graybiel, A.M.: The fronto-striatal projection in the cat and monkey and its relationship to inhomogeneities established by acetylcholinesterase histochemistry. Brain Res., 208: 259-266, 1981.

33) Reale, R.A. and Imig, T.J.: Auditory cortical field projections to the basal ganglia of the cat. Neurosci., 8: 67-86, 1983.

34) Reep, P.L. and Winans, S.S.: Efferent connections of dorsal and ventral agranular insular cortex in the hamster, Mesocricetus autatus. Neurosci., 7: 2609-2635, 1982.

35) Royce, G.J.: Autoradiographic evidence for a discontinuous projection to the caudate nucleus from the centromedian nucleus in the cat. Brain Res., 146: 145-150, 1979.

36) Saper, C.B.: Convergence of autonomic and limbic connections in the insular cortex of the rat. J. comp. Neur., 210: 163-173, 1982.

37) Sar, M., Stumpf, W.E., Miller, R.J., Chang, K.-J. and Cuatrecasas, P.: Immunohistochemical localization of enkephalin in rat brain and spinal cord. J. comp. Neur., 182 17-38, 1978.

38) Tanaka, D., Jr.: Corticostriate projections from reciprocally connected sectors of areas 4 and 5 in the dog. Exp. Neur., 80:613-621, 1983.

39) Unnerstall, J.R., Molliver, M.E., Kuhar, M.J. and Palacios, J.M.: Ontogeny of opiate binding sites in the hippocampus, olfactory bulb and other regions of the rat forebrain by autoradiographic methods. Dev. Brain Res., 7: 157-169, 1983.

40) Van Hoesen, G.W., Yeterian, E.H. and Lavizzo-Mourey, R.: Widespread corticostriate projections from temporal cortex of the rhesus monkey. J. comp. Neur., 199: 205219, 1981.

41) Wamsley, J.K., Zarbin, M.A., Young, W.S. and Kuhar, M.J.: Distribution of opiate receptors in the monkey brain: an autoradio graphic study. Neurosci., 7: 595-613, 1982.

42) Webster, K.E.: Cortico-striate interrelations in the albino rat, J. Anat. (Lond.), 95: 532-544, 1961.

43) White, E.L. and DeAmicis, R.A., Afferent and efferent projections of the region in mouse SmI cortex which contains the posteromedial barrel subfield. J. comp. Neur., 175: 455-482, 1977.

44) Williams, R.G. and Dockray, G.J.: Distribution of enkephalin-related peptides in rat brain: immunohistochemical studies using antisera to metenkephalin and met-enkephalin Arg ${ }^{6}$ Phe ${ }^{7}$. Neurosci., 9: 563-586, 1983.

45) Yeterian, E.H. and Van Hoesen, G.W.: Cortico-striate projections in the rhesus monkey: The organization of certain cortico-caudate connections. Brain Res., 139: 43-63, 1978. 


\section{Explanation of Figure}

\section{Plate I}

Fig. 2. Dark field photomicrographs showing the distribution of frontostriatal fibers at the anterior onefifth (A) and one-third (B) levels. Irregularly shaped, sparsely labeled patches (striosome-like structures) are evident in both photographs. The bar in Fig. $2 \mathrm{~A}$ represents $1 \mathrm{~mm}$. Magnifications of the following photomicrographs are the same as that of Fig. $2 \mathrm{~A}$. 


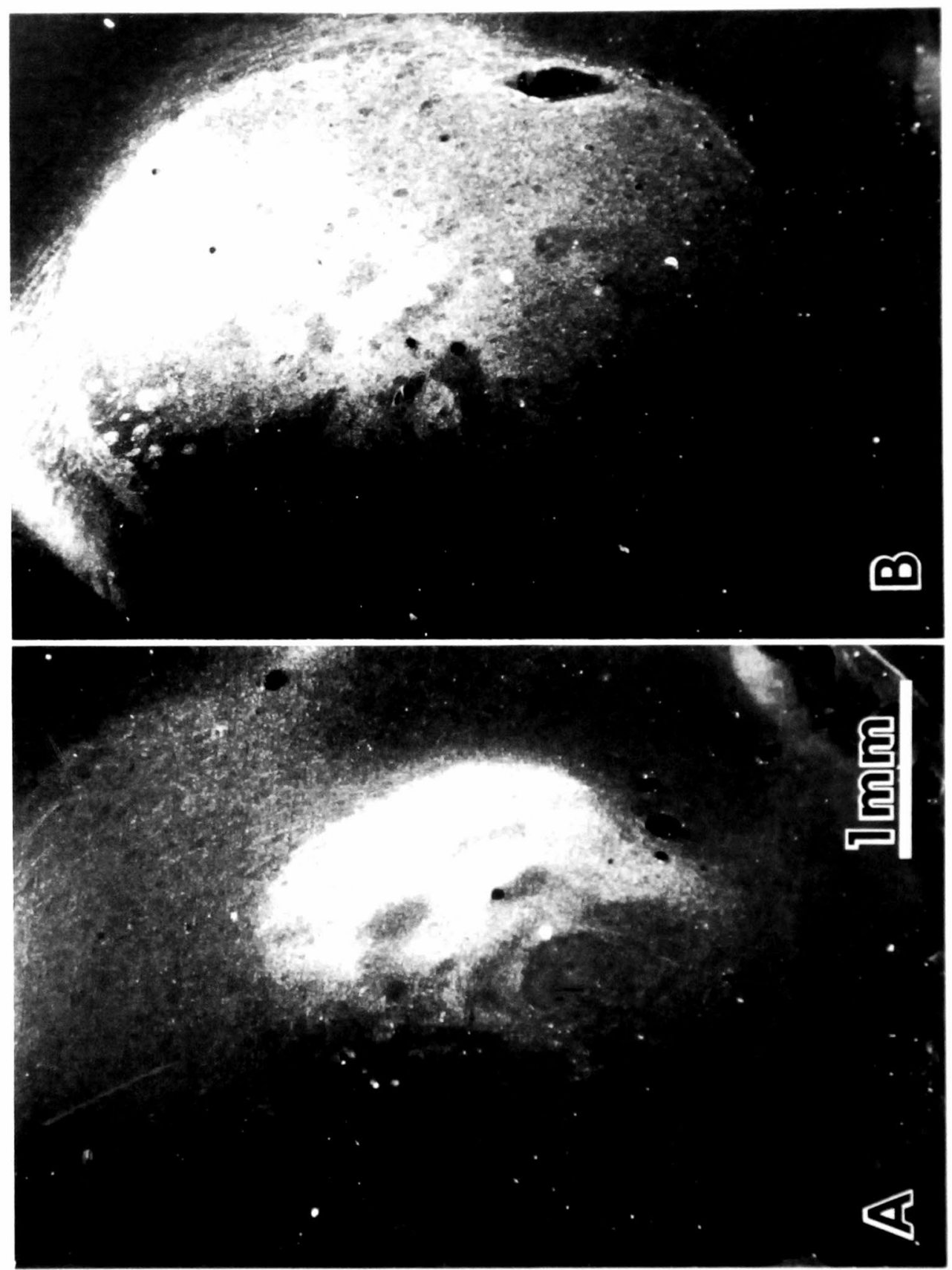




\section{Plate II}

Fig. 3. Dark field photomicrographs showing the distribution of frontostriatal fibers at the anterior twothirds (A) and half (B) levels of the striatum. Striosome-like structures are not observed. Some patchor lamella-like aggregations of silver grains are located in the ventromedial portion of the striatum in Fig. B. 

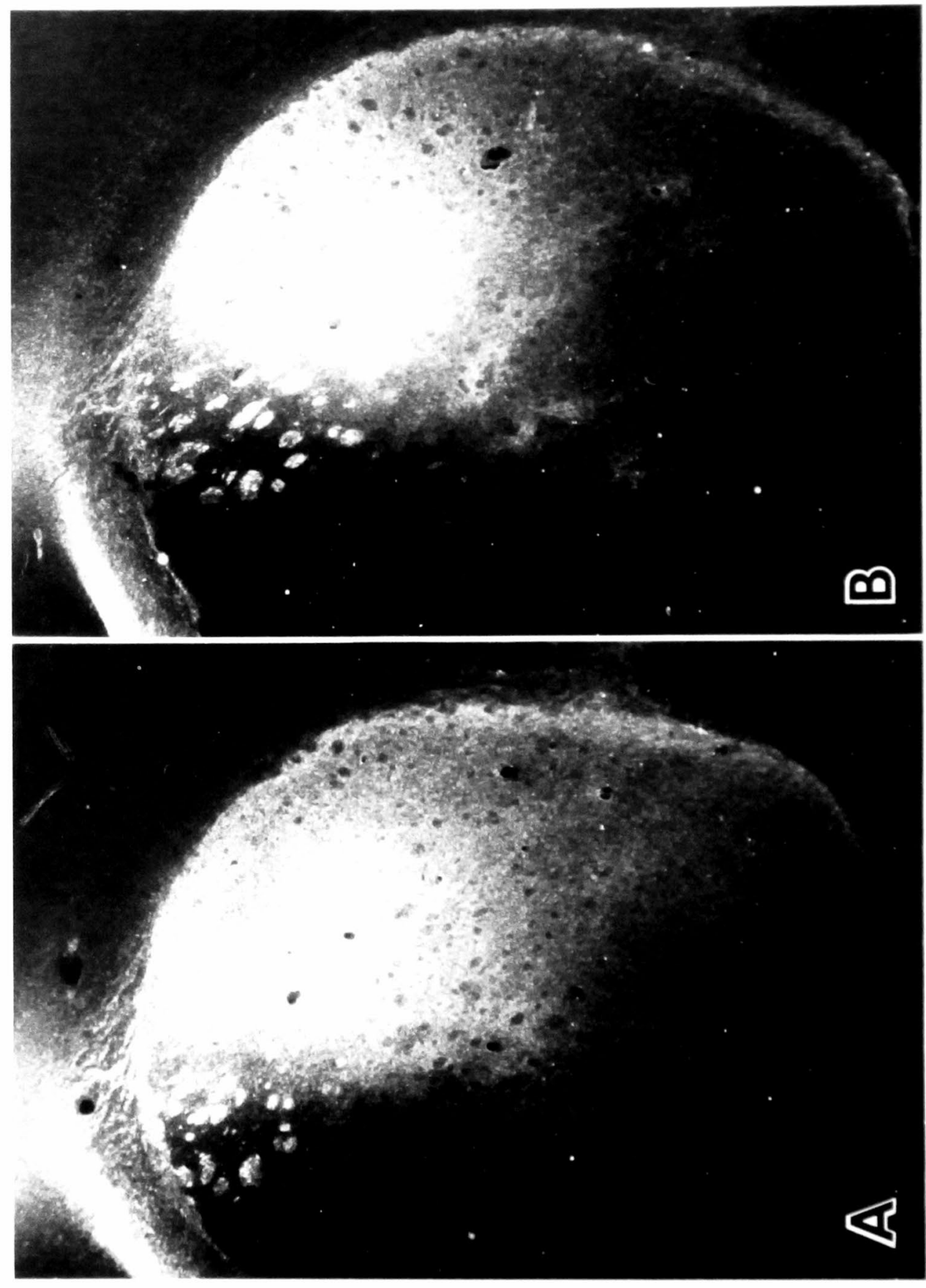


\section{Plate III}

Fig. 4. Dark field photomicrographs showing the distribution of frontostriatal fibers at the posterior twofifths (A) and one-fourth (B) levels. 


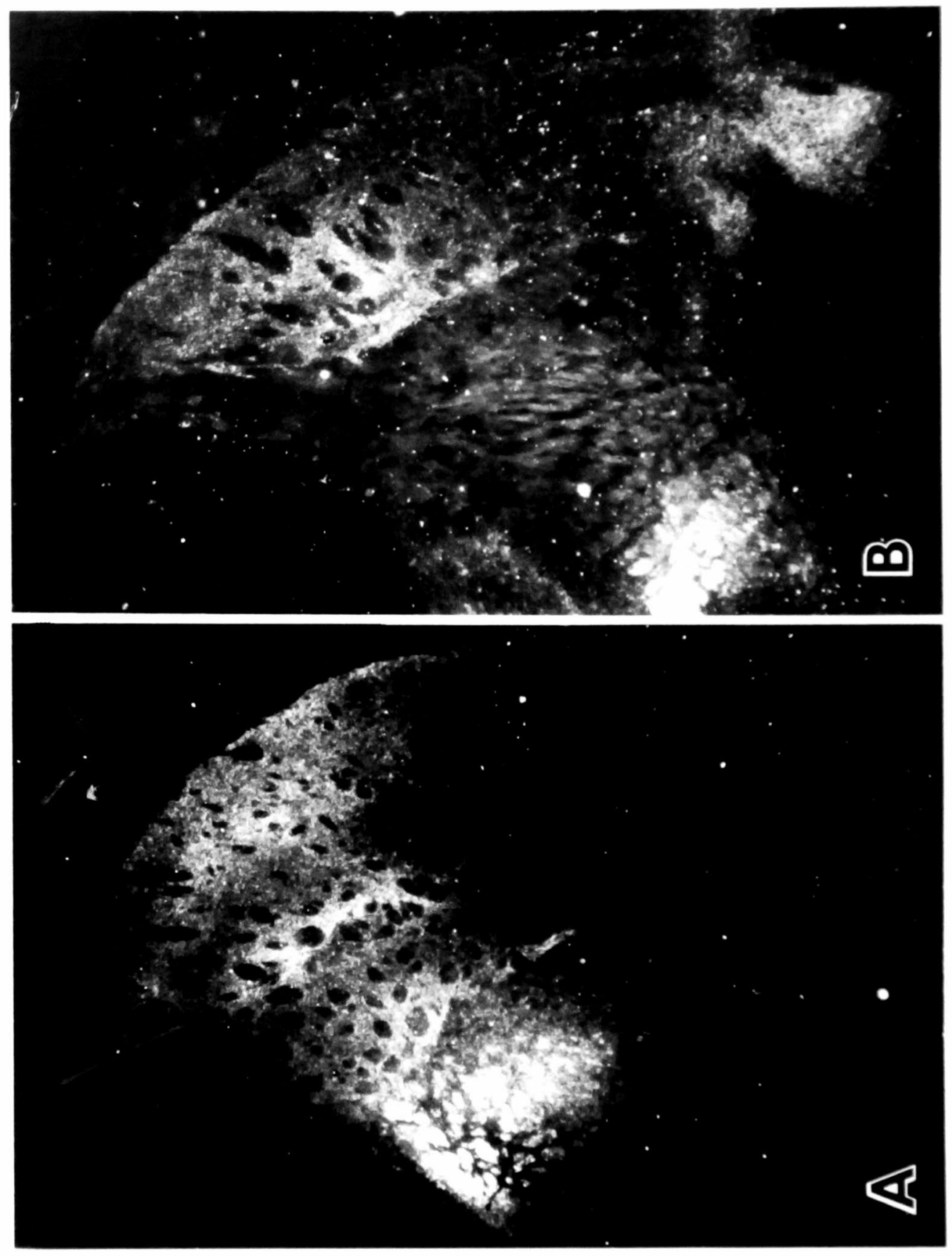




\section{Plate IV}

Fig. 5. Dark field photomicrographs showing distribution of parietostriatal fibers at the posterior one-fifth (A) and posterior one-third (B) levels of the striatum. 


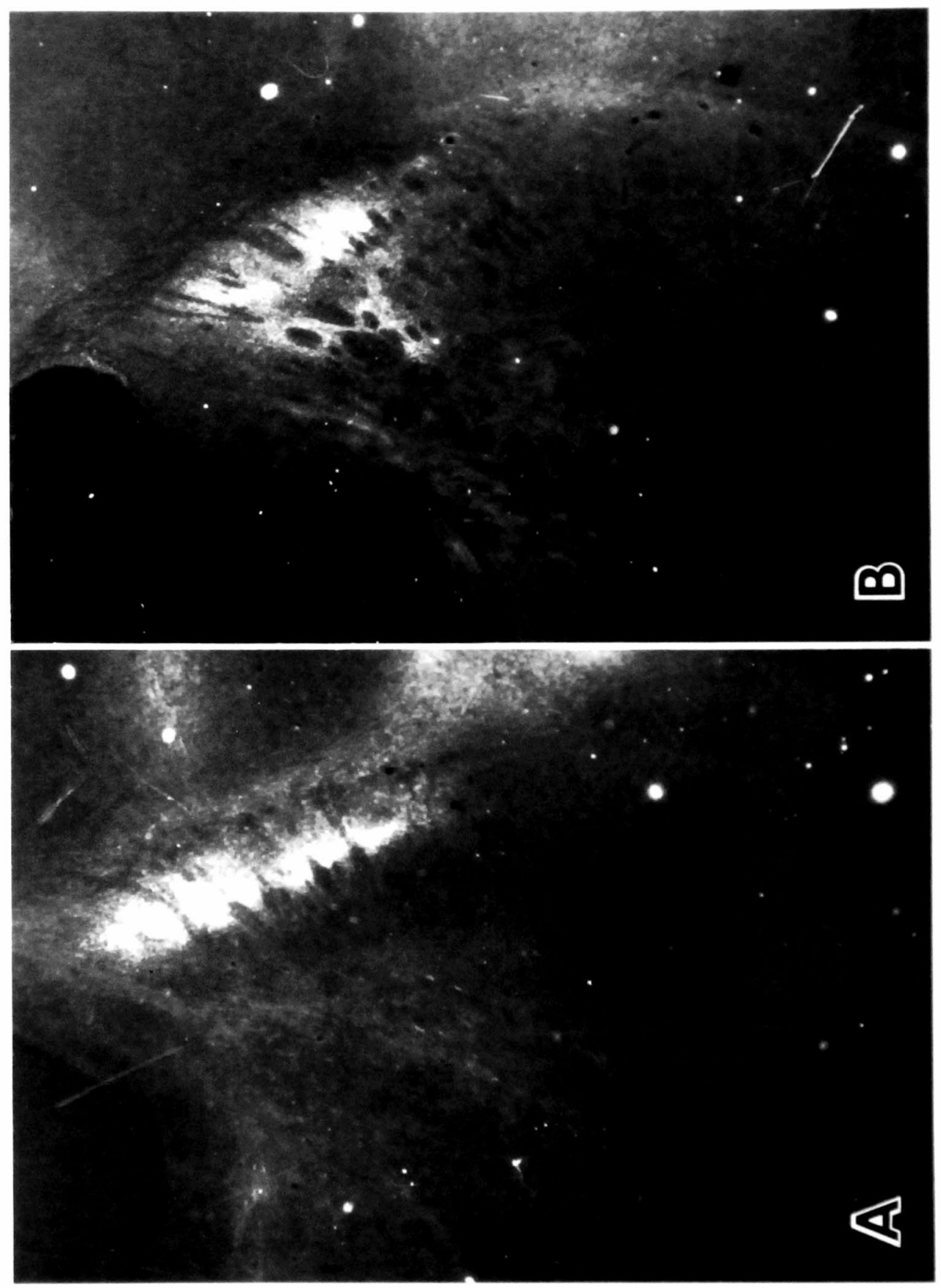

